Qishen Chen, Feng Xue*, and Enyong Ding

\title{
Preparation of POSS-triol/wollastonite composite particles by Liquid phase mechanochemical method and its application in UV curable coatings
}

https://doi.org/10.1515/secm-2019-0001

Received Dec 11, 2018; accepted Mar 07, 2019

\begin{abstract}
POSS-coated wollastonite composite particles were prepared by the liquid phase mechano-chemical grinding of wollastonite and POSS powder together in the high pressure homogenizer [1-4] for the first time. And then we prepare UV curable coatings of vinyl trimethoxy silane(VTMS) / butyl acrylate (BA) with different content of composite particles [5]. Nuclear magnetic resonance spectroscopy, scanning electron microscopy and infrared spectra were used to investigate the microstructures and morphologies of the composite. The properties of the coatings are tested by FTIR, SEM, water contact angles and so on. The results indicate that the POSS was successfully loaded on the surface of silica fume to prepare composite particles and when the addition of the composite particles is $12 \%$, the water contact angle of the UV curable coating reaches $151.96^{\circ}$, and the mechanical properties of the coating are also qualified.
\end{abstract}

Keywords: Wollastonite; composite particles; superhydrophobic; UV coating

\section{Introduction}

In recent years, the super-hydrophobic material has attracted much interest. Because it has the unique properties like self-cleaning, super-hydrophobic and other surface properties, and it has potential application value in

\footnotetext{
^Corresponding Author: Feng Xue: College of Materials Science and Engineering, South China University of Technology, Guangzhou 510000 Guangdong, People’s Republic of China; Email: psfxue@scut.edu.cn

Qishen Chen: College of Materials Science and Engineering, South China University of Technology, Guangzhou 510000 Guangdong, People's Republic of China; Email: 376034600@qq.com

Enyong Ding: College of Materials Science and Engineering, South China University of Technology, Guangzhou 510000 Guangdong, People’s Republic of China; Email: eyding@scut.edu.cn
}

the direction of construction, navigation, automobile and daily necessities [6-8]. The various methods to prepare super-hydrophobic surfaces has become a hot spot. And how to apply the super-hydrophobic surfaces in coatings, especially UV curable coatings, has become the difficulties in the field of coatings.

Many studies have shown that wollastonite [9-11], which has silica properties like mechanical properties on the surface $[12,13]$, is prepared by an orderly combination of silica particles and wollastonite [14], which can lead to the roughness of the wollastonite particles, eliminate the angle, improve the bonding strength of wollastonite to the matrix, and improve the application performance of wollastonite. However, the dispersivity of the silica / wollastonite composite particles prepared by the traditional solid-phase mechanochemical method [15] is poor and its performance is limited and unstable. Beaucase of the dry system, the nuclear particles and the shell particles are combined only by the intermolecular force like the Van der Waals' force and the electrostatic force $[16,17]$. Under the condition of liquid medium (mainly water), the liquid phase mechanochemical method is a new method of preparing the coated composite particle material by activating the solid particles by mechanical grinding and finally triggering the interfacial reaction of the particles. This method can solve the problems existing in the solidphase mechanochemical method $[18,19]$.

In high pressure homogenizer, the high pressure reciprocating pump is power transmission and the material conveying mechanism transfers material to the working valve part. In the process of passing through the working valve, the liquid material or solid particles with liquid as the carrier are refined under a strong shear, impact and hole action (Figure 1) [20, 21]. The effect of high pressure homogenizer on material is also a liquid mechanochemical method [22, 23]. It is rarely reported that the preparation of composite particles by high pressure homogenization mechanism. High pressure homogenizer can make the particle size fine and exposing more hydroxyl groups on the fracture surface [24], leading the hydroxyl association

๖ Open Access. ( 2019 Q. Chen et al., published by De Gruyter. (CC) BY License 
and the binding degree between the core and shell particles increased. This is a new method to prepare composite particles.

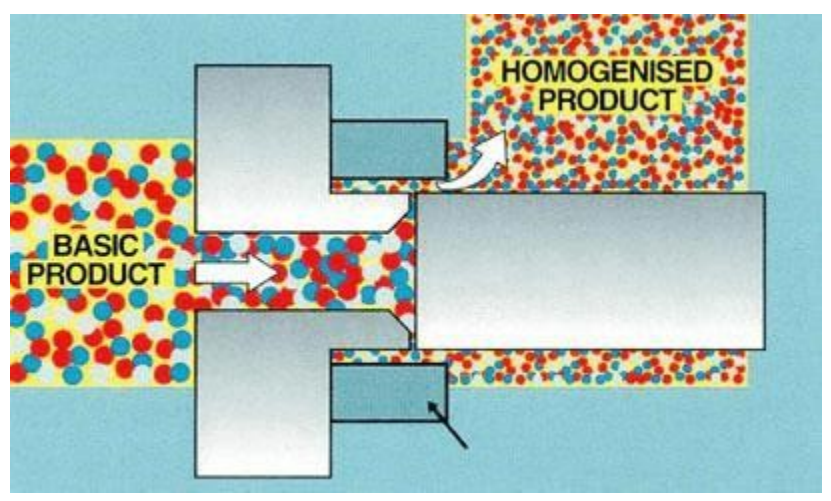

Figure 1: Working principle of high pressure homogenizer

UV curable coatings have the advantages that many traditional coatings didn't have [25], such as high efficiency, low consumption, green pollution and so on. The UV curable coatings have achieved rapid development and attracted the attention of scientists [26, 27]. The preparation of organosilicon materials by light curing have both excellent properties of organosilicone materials $[28,29]$ and the characteristics of high efficiency and energy saving of light curing technology. Moreover, the organic / inorganic two phase compatibility is good, and the mechanical properties of the materials are excellent, and it has a broad application prospect [30]. However, the focus of the present study is to mix nano silica after surface modification into the light solidified organosilicon system, in order to improve the hardness, strength and wear resistance of the coatings [31, 32], and few studies have been made on the preparation of superhydrophobic coatings by UV curing. And the use of wollastonite composite particles to prepare the superhydrophobic surface has not been reported.

In this paper, POSS-triol / wollastonite composite particles are prepared by liquid phase mechanochemical method of high pressure homogenizer, and hybrid particles are added to UV curing coatings in different proportions to prepare hybrid light curing coatings. The properties of the coatings are tested by FTIR, SEM, water contact angles and so on. The influence of particle size on the properties of coatings was studied. A superhydrophobic composite particle light curing hybrid coating with good mechanical properties was prepared.

\section{Experimental}

\subsection{Materials}

Vinyltrimethoxysilane(VTMS) and phenyltrimethoxysilane were obtained from Jingzhou Jianghan Fine Chemical Co., China. Wollastonite was purchased from Guangdong wuling wollastonite co., China. 1-Hydroxycyclohexyl phenyl ketone(photoinitiator 184) was purchased from Macklin's Reagent Company. The solvents such as tetrahydrofuran (THF), acetic acid glacial, methanol, butyl acrylate were of chemically pure grade, also obtained from commercial resources. And sodium hydroxide $(\mathrm{NaOH})$ were of chemically pure grade, purchased from Fuchen(Tianjin) Reagent Co., China.

\subsection{Preparation of heptamertic phenyl silsesquioxane trisilanol(POSS-triol)}

$195 \mathrm{~mL}$ tetrahydrofuran, $3.0803 \mathrm{~g}(0.077 \mathrm{~mol})$ sodium oxide,

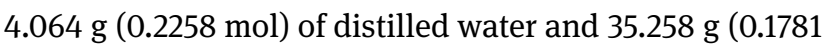
mol) phenyltrimethoxysilane were added into three flasks in turn, and then refluxed and heated for 5 hours after mixing. Then the reaction was dropped to the room temperature to continue to react to $15 \mathrm{~h}$. The obtained suspension was poured into the suction funnel for filtration, and the filter cake was dissolved in $115 \mathrm{ml}$ methanol. After dissolved completely, then the solution neutralized by adding $115 \mathrm{ml}$ glacial acetic acid( $3 \mathrm{~mol} / \mathrm{L})$. The filtrate was removed and the filter cake was washed with deionized water for 3 times. The obtained white solid was dried in a vacuum oven for $24 \mathrm{~h}$, and the target product polysiloxane was obtained (Figure 2).

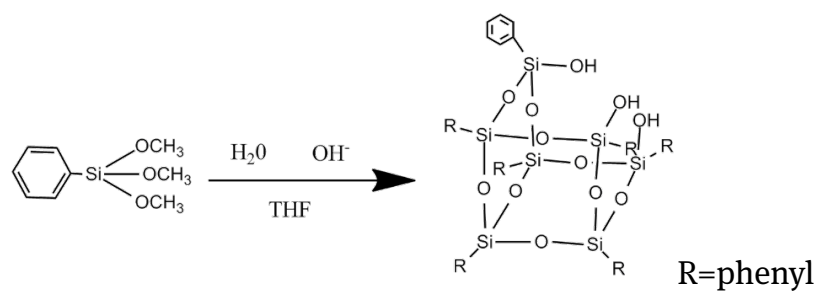

Figure 2: Synthesis of POSS-triol 


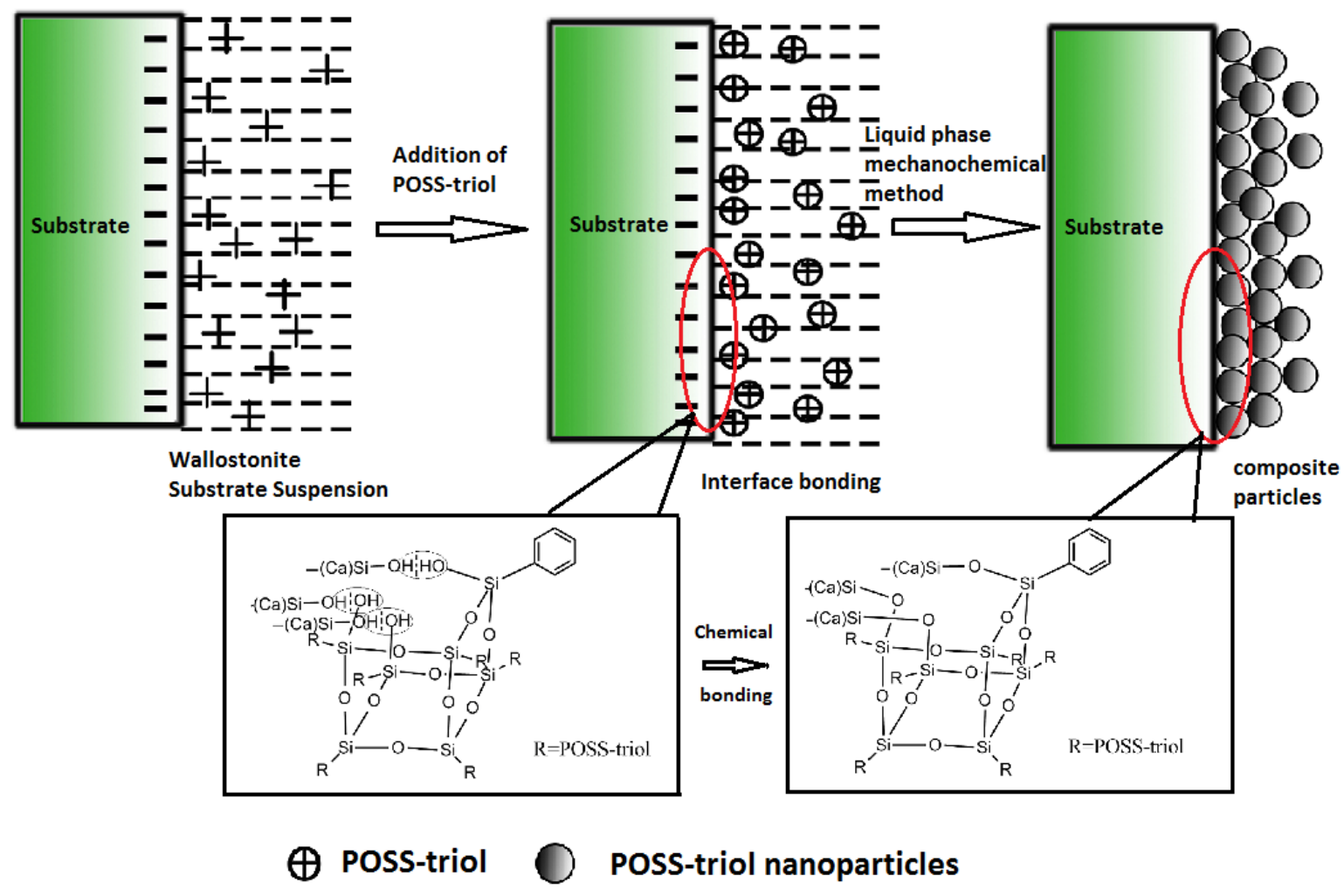

Figure 3: Synthesis of POSS-triol/ wollastonite composite particles

\subsection{Preparation of POSS-triol/ wollastonite composite particles}

The preparation process of composite particles is shown in Figure 3. After weighing wollastonite, polysesquisiloxane and water according to certain quality, they are put into plastic bottles and stirred for half an hour under magnetic stirring to prepare milky white suspension with slurry concentration of $1 \%$. After mixing and under the liquid phase mechanochemical action of high pressure homogenizer, the turbid liquid of POSS-triol/ wollastonite composite particles after treatment is obtained by adjusting the pressure of high pressure homogenizer and the number of homogenization. The filter cake after suspension filtration was dried in vacuum oven for $24 \mathrm{~h}$, and POSS-triol / wollastonite composite particles were obtained. The specific reaction process is as follows:

\subsection{Preparation of UV curable coatings doped with POSS-triol / wollastonite composite particles}

The postoptimality composite particles(homogenization pressure:12 MPa, homogenization:4 times, slurry concentration: $1 \%$, POSS content: $40 \%$.) , vinyl trimethoxy silane, butyl acrylate and 1- hydroxycyclohexyl benzophenone are proportioning in a certain proportion, and then it is stirred by magnetic stirring. After mixing, the hybrid solution is obtained. It is coated on the clean slide glass by roll coating and put into the UV curing box $\left(100 \mathrm{mw} / \mathrm{cm}^{2}\right)$, and it is irradiated for a certain time at a distance of $10 \mathrm{~cm}$ from the UV lamp. Under the combined action of ultraviolet radiation and ultraviolet photoinitiator, the double bond on vinyl trimethoxy silane and the double bond on butyl acrylate were polymerized by free radical polymerization, solidified into a film, and after drying at room temperature for $24 \mathrm{~h}$, the composite particle hybrid superhydrophobic coating was obtained. 


\subsection{Characterizations}

\subsubsection{Fourier transform infrared spectroscopy (FTIR)}

The FTIR measurements were conducted on a VERTEX 70/70v Fourier transform research spectrometer at room temperature $\left(25^{\circ} \mathrm{C}\right)$. The sample films of UV curable coatings were prepared by dropping on the $\mathrm{KBr}$ tablet. The samples of POSS-triol/ wollastonite composite particles were mixed with the powder of $\mathrm{KBr}$ and then pressed into the small flakes.

\subsubsection{Nuclear magnetic resonance spectroscopy (NMR)}

The ${ }^{1} \mathrm{H}^{13} \mathrm{C}$ and ${ }^{29} \mathrm{Si} \mathrm{NMR}$ measurements were carried out on a Bruker Avance III $400 \mathrm{~Hz}$ NMR spectrometer. The samples were dissolved with deuterated chloroform and the solutions were measured with tetramethylsilane (TMS) as the internal reference.

\subsubsection{Thermogravimetric analysis (TGA)}

An America TA Q5000IR thermal gravimetric analyzer (TGA- Q5000IR) was used to investigate the thermal stability of the hybrids. The samples (about $10 \mathrm{mg}$ ) were heated under nitrogen atmosphere from ambient temperature to $800^{\circ} \mathrm{C}$ at the heating rate of $10^{\circ} \mathrm{C} / \mathrm{min}$. The temperature of the extrapolated onset was taken as the thermal degradation temperature.

\subsubsection{X-ray diffraction (XRD)}

The XRD analyses were conducted on a PANalytical X'Pert X-ray powder diffractometer (XRD, Panalytical Corporation, Holand) operated with $\mathrm{Cu} \mathrm{K} \alpha$ radiation at $30 \mathrm{kV}$ and $10 \mathrm{~mA}$ and with a scanning speed of $2(2 \theta) / \mathrm{min}$.

\subsubsection{Laser Particle Size Analyzer}

The particle size of the composite particles was tested in a Beckman Coulter laser particle size analyzer. The composite particle aqueous solution was prepared at a concentration of $2 \%$ and dispersed evenly through the ultrasonic cleaning machine.

\subsubsection{Scanning electron microscope}

The microstructure and morphologies were investigated by scanning electron microscope (SEM, NOVA 430, FEI, Holand).

\subsubsection{Contact angle measurements}

The flat free surfaces of the UV curable coatings were used for the measurement of contact angle. The static contact anglemeasurements with the probe liquids (i.e., ultra-pure water) were carried out on a German KRUSS, DSA30 Research Contact Angle Measuring Instrument at room temperature(drop volume is $5 \mu \mathrm{L}$ ). The samples were dried at $60^{\circ} \mathrm{C}$ in a vacuum oven for $24 \mathrm{~h}$ prior to measurement.

\subsubsection{High pressure homogenizer}

The composite particles were prepared by high-pressure homogenizer(ATS Engineering Limited AH-500). The optimum parameters of the preparation process were homogenization pressure:12 MPa, homogenization:4 times, slurry concentration: $1 \%$, POSS content:40\%.

\subsubsection{Hardness test}

According to GB/6739-1996:Detennination of film hardness by pencil test, the coating is coated on the iron, the size is $50 \mathrm{~mm}^{\star} 120 \mathrm{~mm}^{\star}(0.2 \sim 0.3) \mathrm{mm}$, the test plate is placed on the horizontal table, the coating is fixed upwards, and the handheld pencil is about 45 angles. When the pencil is not broken, push pressure on the film surface, push about $1 \mathrm{~cm}$ at a uniform speed of about $1 \mathrm{~cm} / \mathrm{s}$ ahead of the tester, scratch on the surface of the film, and repeat five repeats to the pencil of the same hardness mark. In the five scratch test, if there are two or more than two items that the film is not scratched, replace the same pencil hardness mark with the same test. Select the pencil that has been scratched two or two times, and record the hardness number of the pencil after the pencil hardness label number.

\subsubsection{Adhesion determination}

According to the national standard GB/T9286-1988: Paints varnishes-Crosscut test, the coating on the base material (glass) is made in a lattice, and the sample is $25 \mathrm{~mm} \star 25 \mathrm{~mm}$, the number of delimit is $25^{\star} 25$, and the length of each lat- 
tice is $1 \mathrm{~mm}$. Manual cutting is used for drawing, uniform force, smooth cutting speed and no chatter. After cutting, a soft hair brush is used along the two diagonal direction of the lattice and gently reciprocating several times. (the angle of the brush action is 45 degrees to the surface of the coating, and the force keeps consistent). The adhesion of the coating is characterized by observing the number of the remaining film squares remaining on the surface of the leather. The 0 class adhesion force is the best, and the 5 class adhesion force is the worst. $0,1,2$ three grade can meet the general purpose.

\section{Results and discussion}

\subsection{Characterization of heptamertic phenyl silsesquioxane trisilanol(POSS-triol)}

\subsubsection{FTIR spectra of heptamertic phenyl silsesquioxane trisilanol(POSS-triol)}

Shown in Figure 4 are the FTIR spectra of heptamertic phenyl silsesquioxane trisilanol(POSS-triol). On the infrared spectrum, it shows that the $3426 \mathrm{~cm}^{-1}$ is the characteristic absorption peak of telescopic vibration of $\mathrm{O}-\mathrm{H}$, and the $1431 \mathrm{~cm}^{-1}$ is the characteristic absorption peak of the flexural vibration of $\mathrm{O}-\mathrm{H}$, which indicates that the synthetic POSS-triol has a large number of hydroxyl groups; The $3062 \mathrm{~cm}^{-1}$ is a telescopic vibration absorption peak of Ar-H, and the $1596 \mathrm{~cm}^{-1}$ is the characteristic absorption peak of the benzenering, the 737 and $696 \mathrm{~cm}^{-1}$ is the characteristic peak of mono substituted benzene, indicating that POSS-triol has a single substituted phenyl ring on it; The asymmetric stretching vibration peak at the width

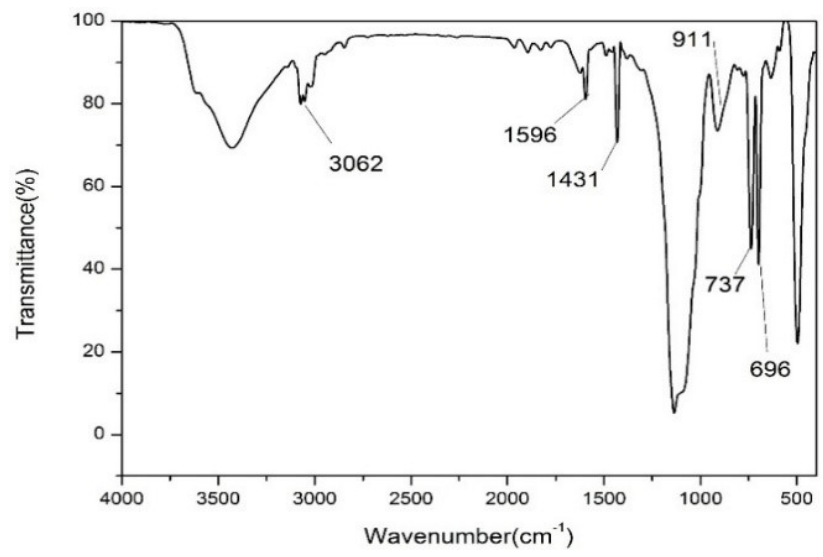

Figure 4: FTIR spectra of heptamertic phenyl silsesquioxane trisilanol(POSS-triol) of $1069-1137 \mathrm{~cm}^{-1}$ is Si-O-Si, indicating that the structure of $\mathrm{Si}$-O-Si in the structure of POSS-triol and the $911.29 \mathrm{~cm}^{-1}$ is the bending vibration absorption peak of $\mathrm{Si}-\mathrm{OH}$. It shows that the infrared spectra of the compounds are basically consistent with the structural peaks of POSS-triol [33].

\subsubsection{NMR spectra of heptamertic phenyl silsesquioxane trisilanol(POSS-triol)}

Shown in Figure 5 are the ${ }^{1} \mathrm{H}$ NMR spectrogram of heptamertic phenyl silsesquioxane trisilanol(POSS-triol). The three peaks are corresponding to three different chemical environments of $\mathrm{H}$ on POSS-triol. ${ }^{1} \mathrm{H} \mathrm{NMR}(\mathrm{ppm}, \mathrm{CDCl} 3)$ : 3.75(s,3.0H,-OH).5.30(dd,7.0H, para- Ar-H).7.26(m,28.0H, ortho- Ar-H, meta- Ar-H).

Shown in Figure 6 are the ${ }^{13} \mathrm{C}$ NMR spectrogram of heptamertic phenyl silsesquioxane trisilanol(POSS-triol) [34]. The four peaks are corresponding to four different chemical environments of C on POSS-triol. ${ }^{13} \mathrm{C} \mathrm{NMR}(\mathrm{ppm}, \mathrm{CDCl} 3)$ : 127.70(dd,14.0C, ortho- C). 128.80(dd,7.0C, Si- C). 130.50(s,7.0C, para- C). 134.10(s,14.0C, meta- C).

Shown in Figure 7 are the ${ }^{29} \mathrm{Si}$ NMR spectrogram of heptamertic phenyl silsesquioxane trisilanol(POSS-triol). The three peaks are corresponding to three different chemical environments of $\mathrm{Si}$ on POSS-triol. ${ }^{29} \mathrm{Si} \mathrm{NMR}(\mathrm{ppm}, \mathrm{CDCl} 3)$ : $-76.88(\mathrm{~s}, 1.0 \mathrm{Si}) .-77.34(\mathrm{~s}, 3.0 \mathrm{Si}) \cdot-78.20(\mathrm{~s}, 3.0 \mathrm{Si})$.

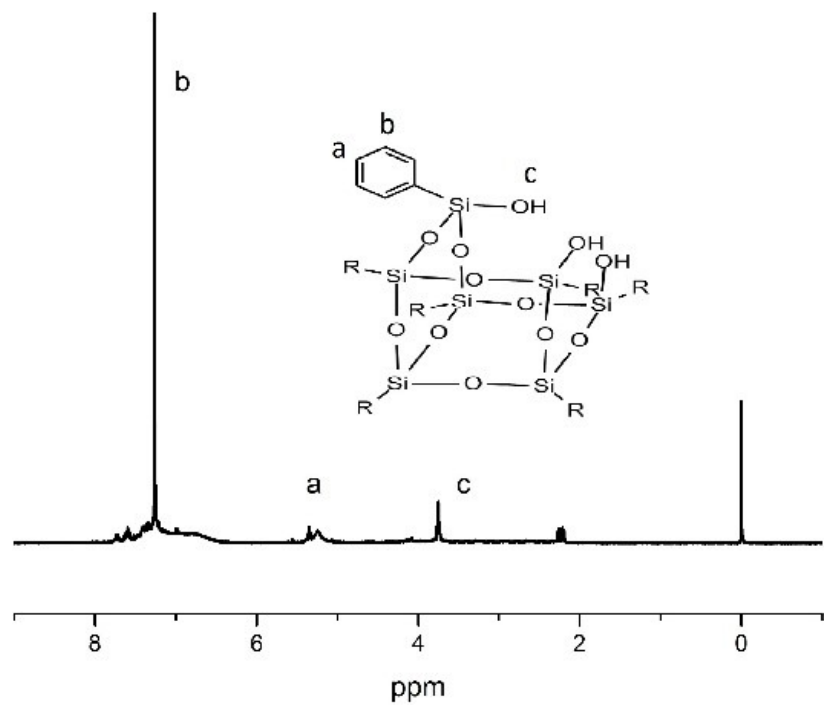

Figure 5: ${ }^{1} \mathrm{H}$ NMR spectrum of heptamertic phenyl silsesquioxane trisilanol(POSS-triol) 


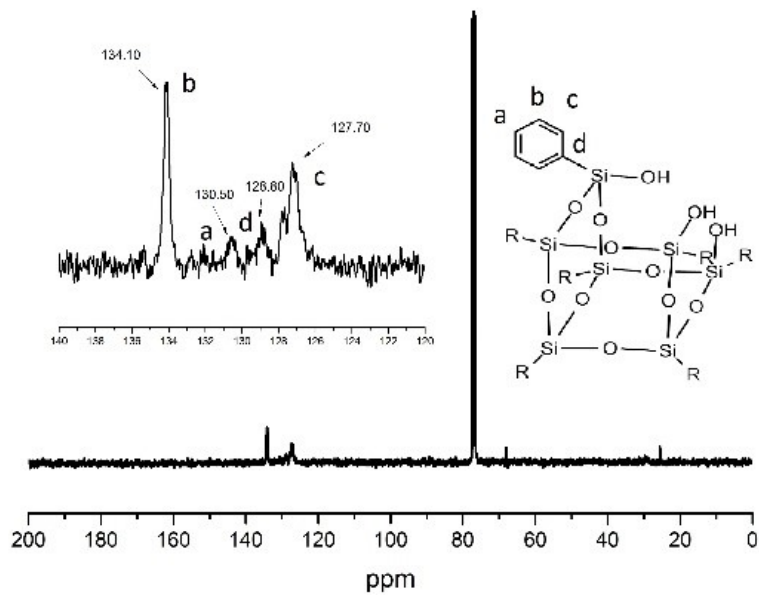

Figure 6: ${ }^{13} \mathrm{C}$ NMR spectrum of heptamertic phenyl silsesquioxane trisilanol(POSS-triol)

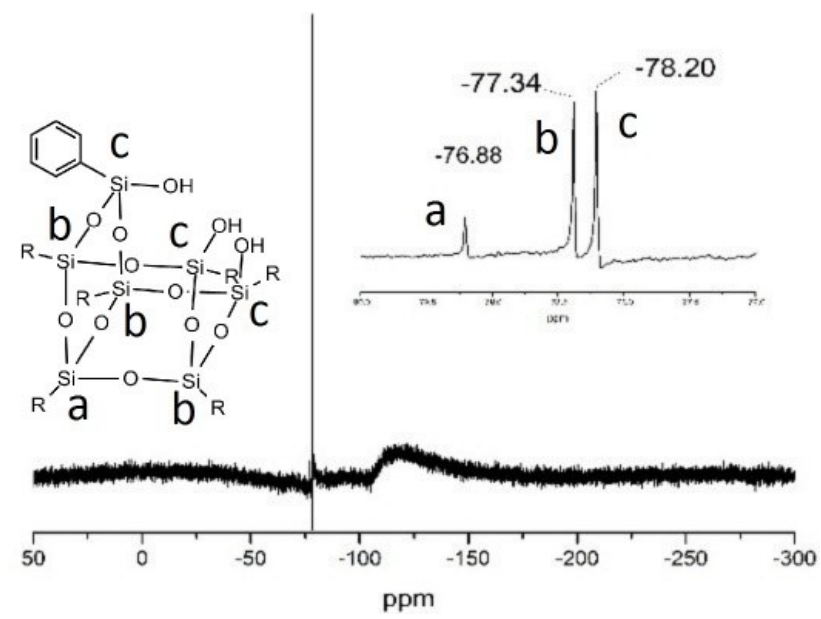

Figure 7: ${ }^{29} \mathrm{Si}$ NMR spectrum of heptamertic phenyl silsesquioxane trisilanol(POSS-triol)

\subsection{Characterization of POSS-triol/ wollastonite composite particles}

\subsubsection{Laser Particle Size Analysis of wollastonite}

The comparison of wollastonite particle size before and after the action of high pressure homogenizer is shown on the Figure 8. From the comparison of the two diagrams, it can be seen that the average particle size of wollastonite decreased from $15.172 \mu \mathrm{m}$ to $10.097 \mu \mathrm{m}$ by the impact and fragmentation of the homogenizer, so the granularity of wollastonite decreased to a certain extent, indicating that the high pressure homogenizer has a certain dispersing and crushing effect on the wollastonite, thus making more hydroxyl groups on the broken surface. It can promote

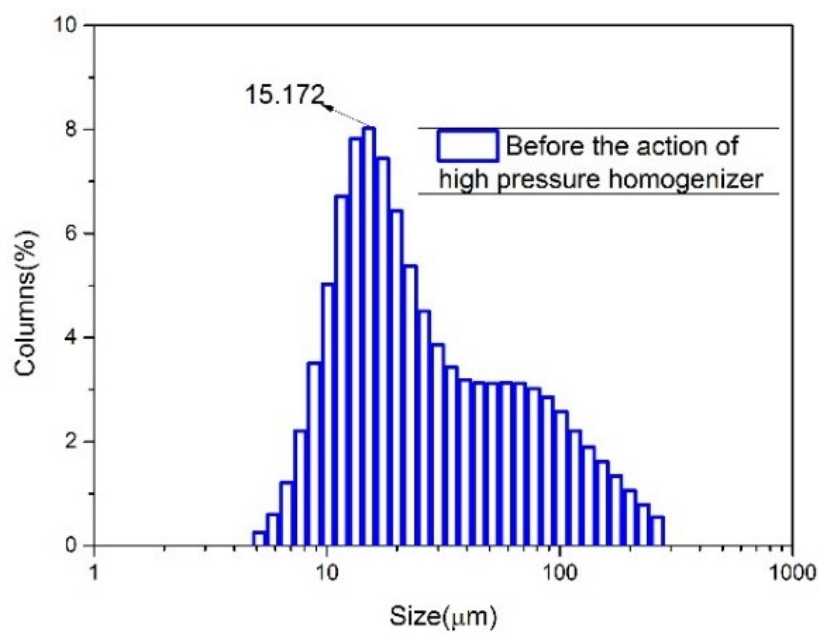

(a)

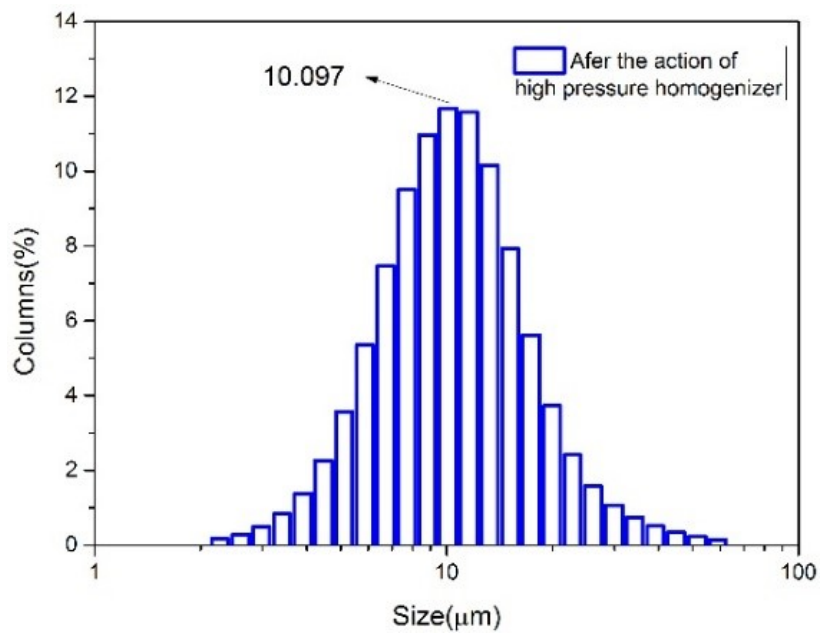

(b)

Figure 8: The comparison of wollastonite particle size before and after the action of high pressure homogenizer: a) before the action b) after the action

the effect of hydroxyl between wollastonite and POSS-triol, and improve its binding degree.

\subsubsection{X-ray diffraction of wollastonite}

Figure 9 is the XRD diagram of wollastonite and its composite particles. The XRD diagram of POSS-triol can be seen in Figure 9a), which shows the wide diffuse peak of the typical nanoscale sample, indicating that the prepared POSStriol is a nanoscale substance. Figure $9 \mathrm{~b}$ ): the peaks of wollastonite on XRD diagram are basically matched with those wollastonite should have, and there are no other hetero peaks, so the purity of wollastonite is relatively high. Figure 8c): the composite particle XRD diagram, there are 


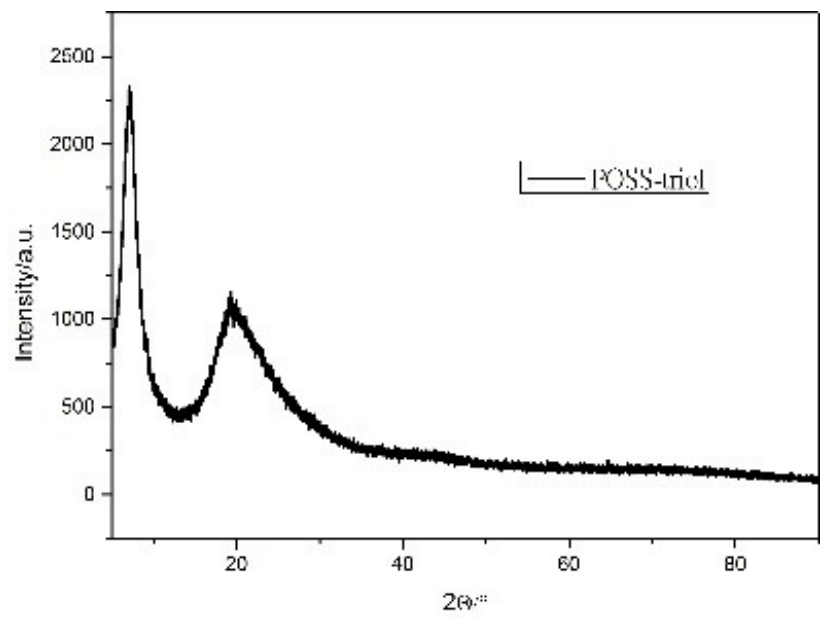

(a)

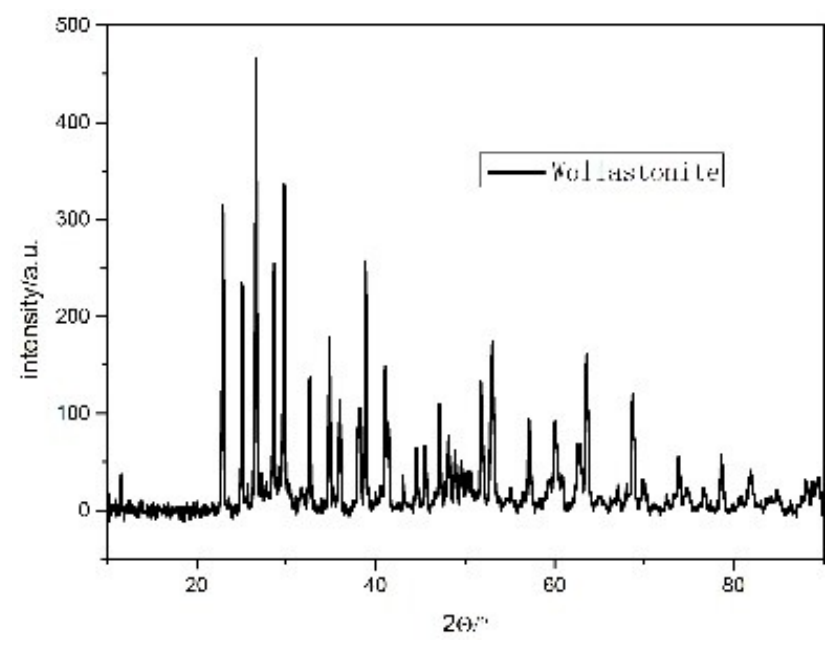

(b)

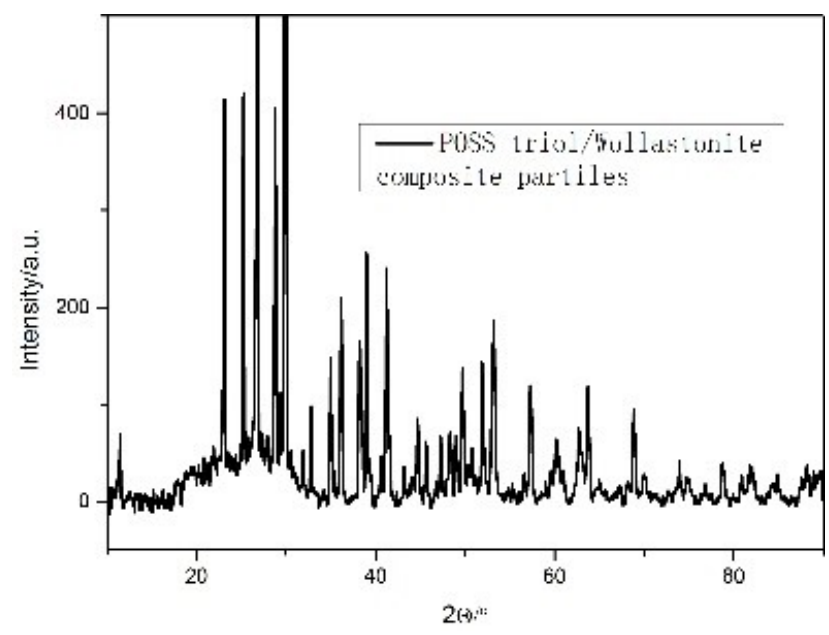

(c)

Figure 9: XRD spectra of wollastonite and its composite particles

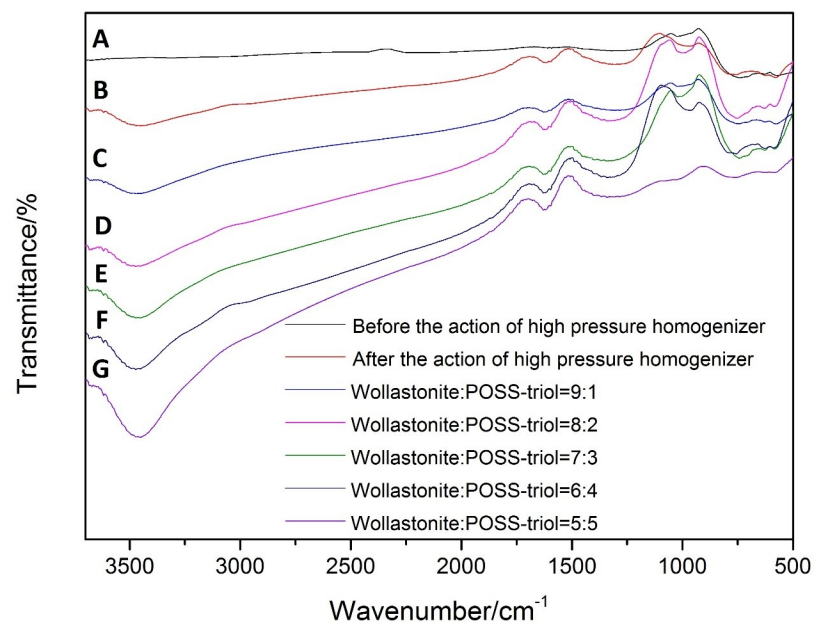

Figure 10: FTIR spectra of POSS-triol/ wollastonite composite particles with different POSS-triol content (A) Before the action of high pressure homogenizer; (B) After the action of high pressure homogenizer;(C) Wollastonite:POSS-triol=9:1; (D) Wollastonite:POSS-triol= 8:2; (E) Wollastonite:POSS-triol=7:3; (F) Wollastonite:POSS-triol= $6: 4 ;$ (G) Wollastonite:POSS-triol= 5:5

both the broad diffuse peaks of the typical nanoscale samples and the sharp diffraction peaks of wollastonite, indicating that the composite particles contain both POSStriol and wollastonite, and the wollastonite in the composite particles has good crystal integrity. After combination, only diffraction peaks of the wollastonite and POSS-triol appear in the XRD pattern of composite pigments and no new phase occurred, which means that the composite still kept its original phase composition. These results indicate that the reaction between wollastonite and POSS-triol only occurs on the interfaces.

\subsubsection{FTIR spectra of POSS-triol/ wollastonite composite particles}

Figure 10 is the FTIR spectrum of POSS-triol / wollastonite composite particles increases with the content of POSStriol (POSS-triol :wollastonite). The absorption peak at $3400 \mathrm{~cm}^{-1}$ represents the stretching vibration peak of O$\mathrm{H}$, which represents hydroxyl on the surface of hydroxyl and wollastonite on POSS-triol. It can be seen that the absorption peak of the position of $3400 \mathrm{~cm}^{-1}$ is strong in the FTIR spectrum of the composite particles. And with the increase of POSS-triol, the absorption peak of the composite particles is widening. It shows that the combination of POSS-triol and wollastonite is a strong connective between the hydroxyl groups on the surface of the two particles. For the enhancement of cooperation, it results in widening of the absorption peaks. It is inferred that this is done by con- 


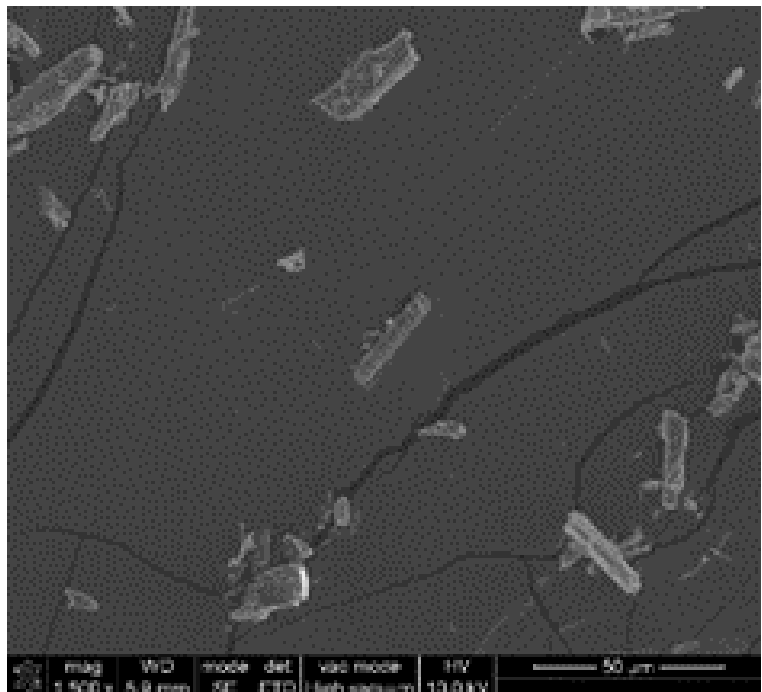

(a)

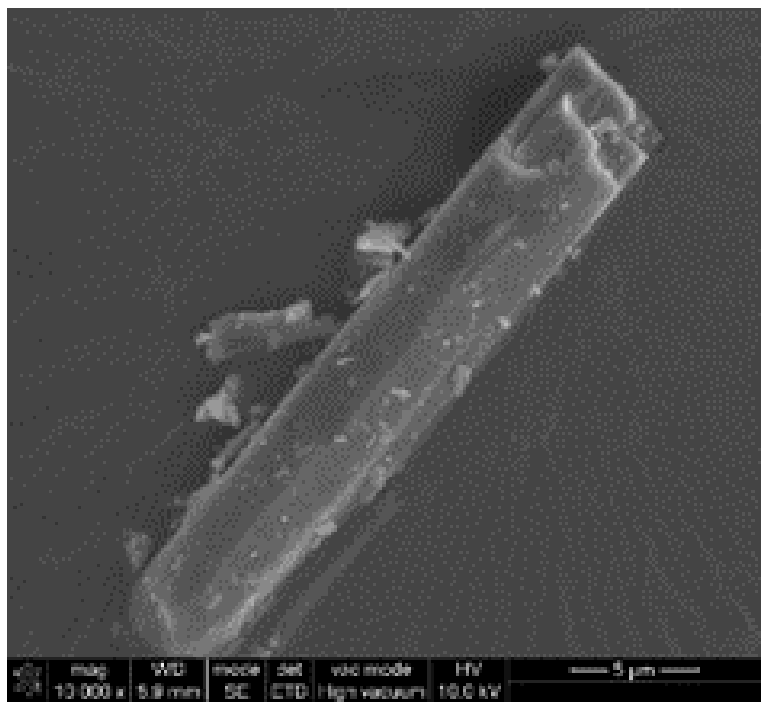

(c)

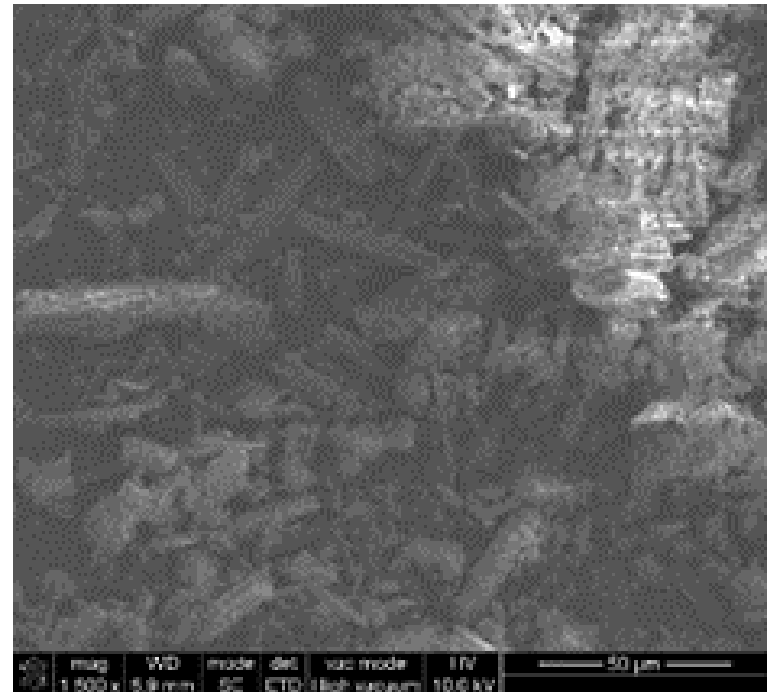

(b)

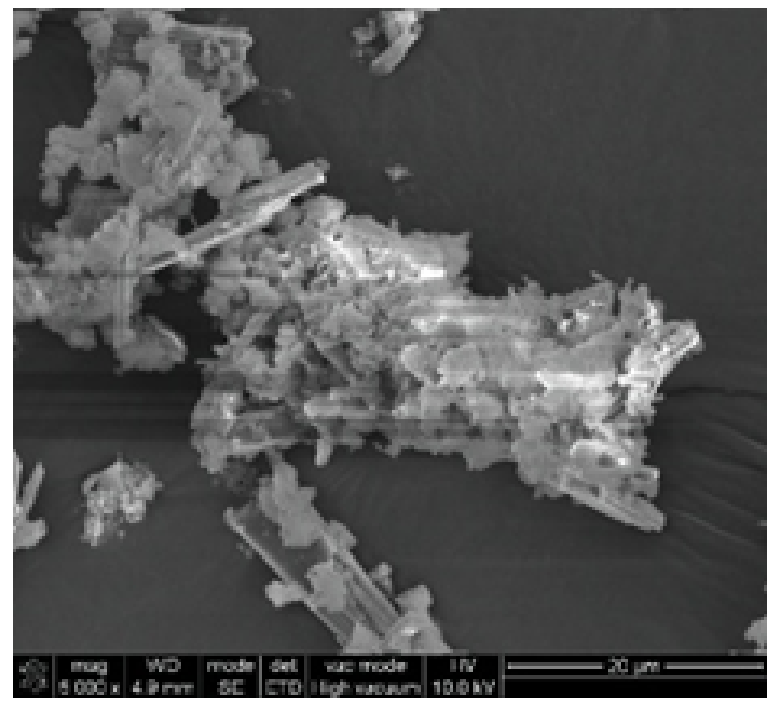

(d)

Figure 11: The SEM images of the wollastonite before and after the compound. a)0\% (Magnify 1500 times); b) $12 \%$ (Magnify 1500 times); c) 0\% (Magnify 10000 times); d) 12\% (Magnify 10000 times)

densation of POSS-triol and wollastonite through the surface hydroxyl groups of each other, and the combination of them has a chemical binding nature [35].

\subsubsection{The Morphology of POSS-triol/Wollastonite Composite}

Figure 11 is the SEM images of the wollastonite before and after the compound. Figure 11b): the needle like wollastonite has a smooth surface and no more other particles, but Figure 11d): the surface of the needle like wol- lastonite in the composite particles has been attached to a large number of POSS-triol particles, making the surface of needle like wollastonite rough, which indicates that POSS-triol has been successfully loaded on the wollastonite, eliminated the angle of the wollastonite and made the surface of the wollastonite rough, and finally, wollastonite is changed from hydrophilic to hydrophobic. 
Table 1: The film formation of different proportions of UV curable acrylate / vinyl trimethoxy silane coatings

\begin{tabular}{cccccc}
\hline Sample & & & VTMS:BA & & \\
& $1: 1$ & $2: 1$ & $3: 1$ & $4: 1$ & $5: 1$ \\
\hline $\begin{array}{c}\text { Coating } \\
\text { condition }\end{array}$ & wrinkled & wrinkled slightly & smooth & produces a slight & produces cracks \\
crack & & and separations \\
\hline
\end{tabular}

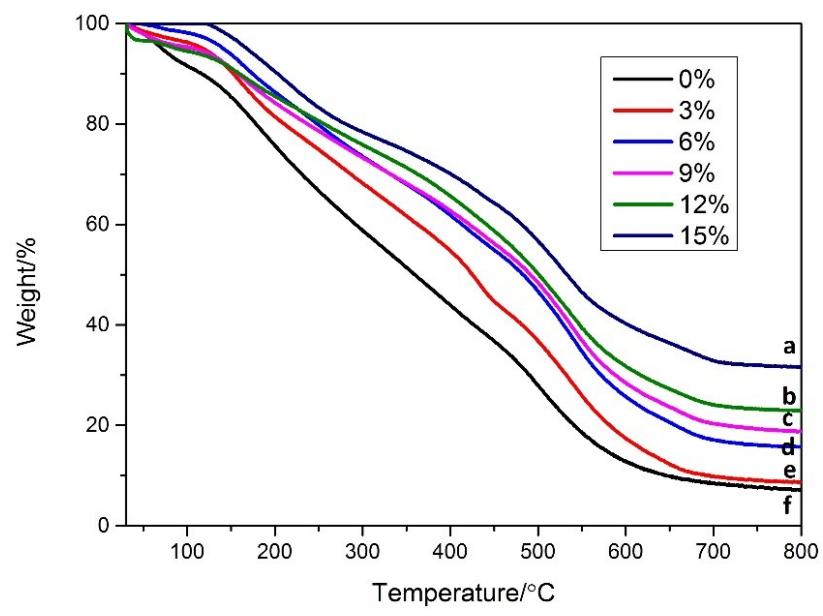

Figure 12: The thermogravimetric curve of VTMS/BA-m- composite particle hybrid coating containing different mass fraction of composite particles. (a) $15 \%$; (b) $12 \%$; (c) $9 \%$; (d) $6 \%$; (e) $3 \%$; (f) $0 \%$

\subsection{Testing of UV curable coatings doped with POSS-triol / wollastonite composite particles}

\subsubsection{Preparation and film formation of UV curable coatings doped with POSS-triol / wollastonite composite particles}

Table 1 is the film formation of different proportions of UV curable acrylate / vinyl trimethoxy silane coatings with vinyl trimethoxy silane (VTMS) and butyl acrylate (BA). It can be seen that when VTMS:BA is 2:1, the coating is wrinkled slightly; when VTMS:BA is 1:1, the coating is wrinkled; when VTMS:BA is 4:1, the coating produces a slight crack; when VTMS:BA is 5:1, the coating produces cracks and separations; and when VTMS:BA is 3:1, the coating is smooth. Therefore, we chose the system when VTMS:BA is 3:1 as a hybrid modification system with composite particles.

\subsubsection{Effect of composite particles content on thermal stability of UV curable Hybrid Coatings}

Figure 12 is the thermogravimetric curve of VTMS/BA$\mathrm{m}$ - composite particle hybrid coating containing different

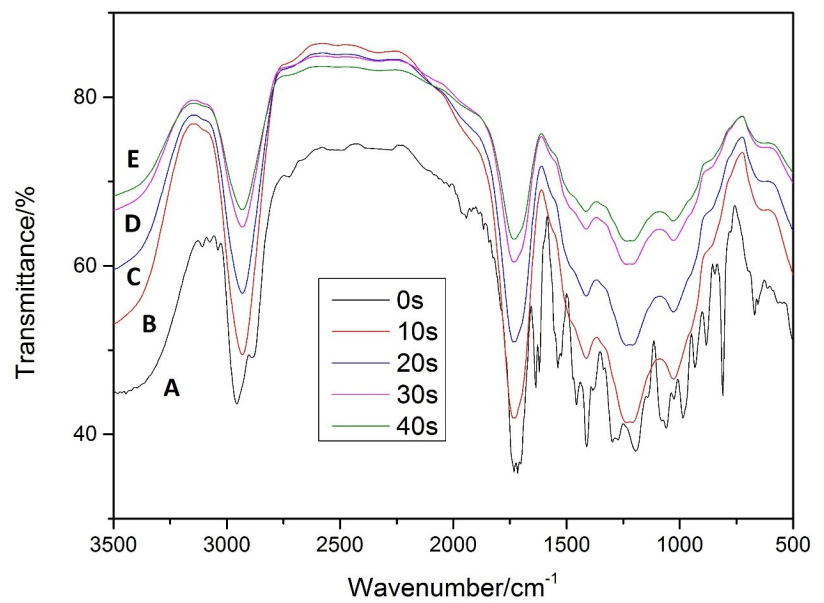

(a)

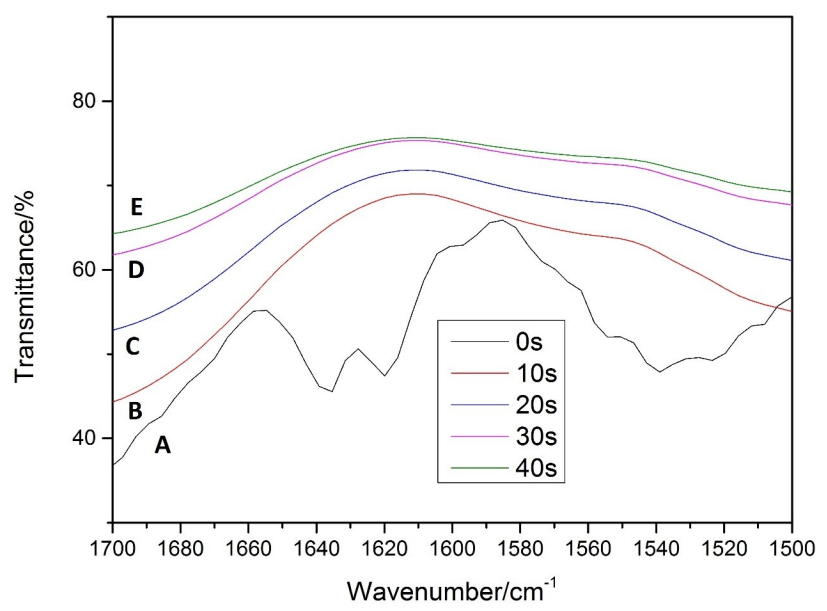

(b)

Figure 13: The FTIR spectra of UV curing hybrid super hydrophobic coatings cured at different times. (A) 0s; (B) 10s; (C) 20s; (D) 30s; (E) $40 \mathrm{~s}$

mass fraction of composite particles. The weightlessness step, which is slightly above $150^{\circ} \mathrm{C}$, is caused by the weight loss of the molecular short chain in the hybrid coating. In the high temperature region, the weightlessness step of $400-550^{\circ} \mathrm{C}$ is the molecular long chain breaking in the hybrid coating. It can be seen from the diagram that the initial decomposition temperature of VTMS/BA-m- composite particle hybrid coatings containing $0 \%, 3 \%, 6 \%, 9 \%, 12 \%$ and $15 \%$ particles in the low temperature region is $152.9^{\circ} \mathrm{C}$, 


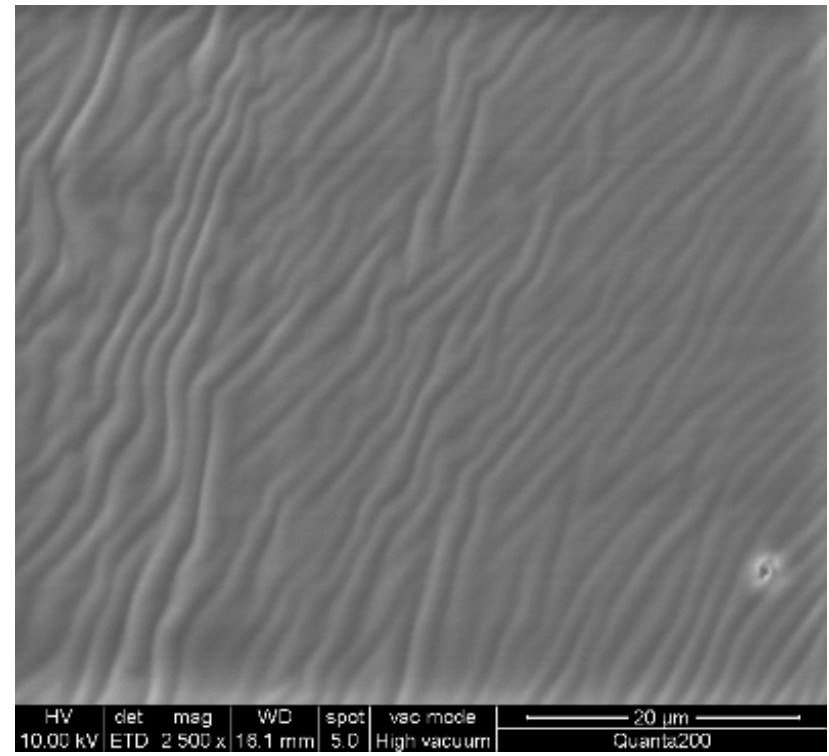

(a)

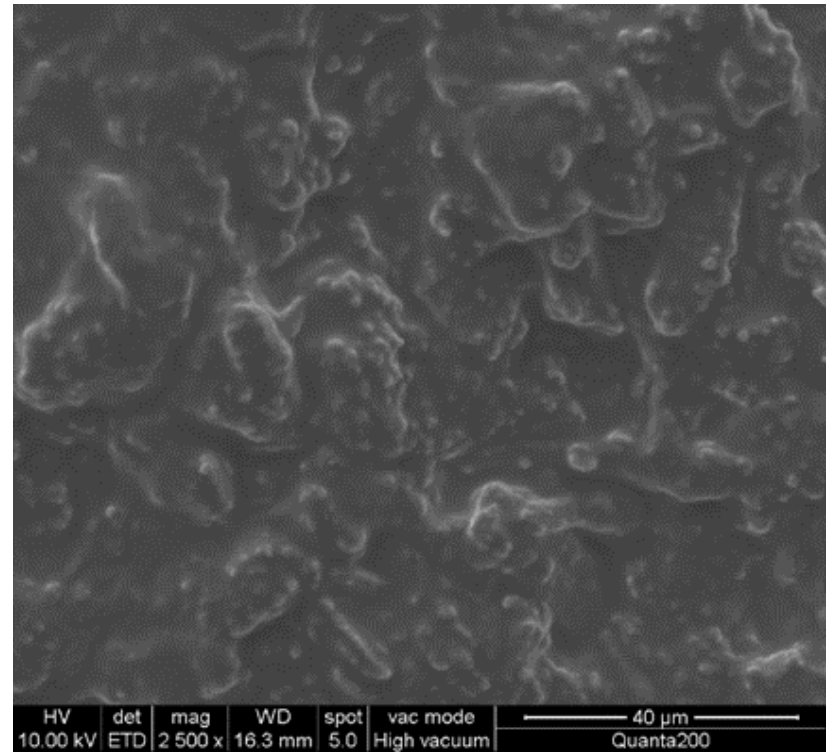

(b)

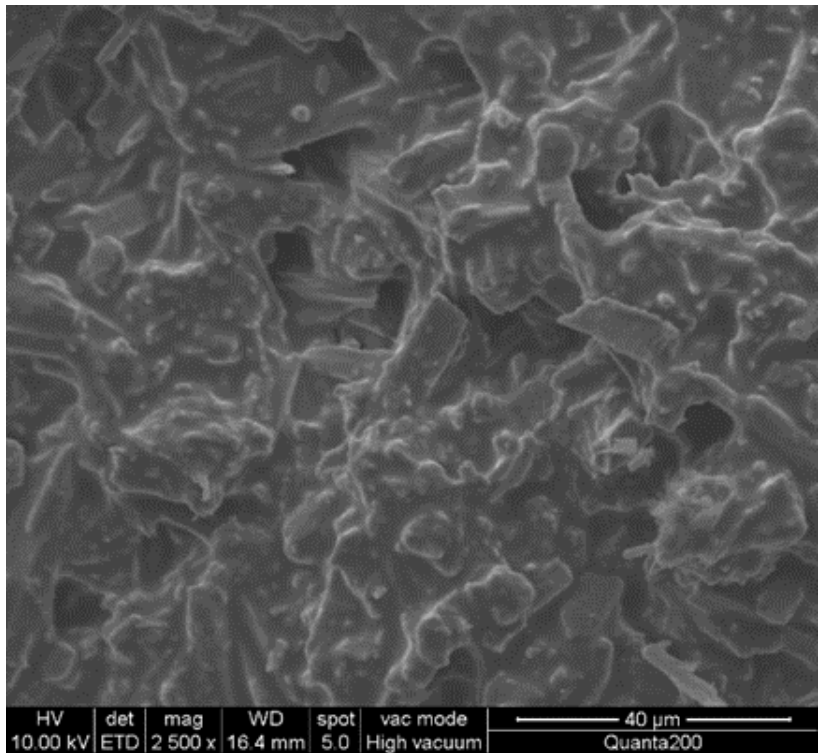

(c)

Figure 14: The SEM images of UV curable Hybrid Coatings. a) $0 \%$; b) $6 \%$; c) $12 \%$

$137.5^{\circ} \mathrm{C}, 126.7^{\circ} \mathrm{C}, 125.4^{\circ} \mathrm{C}, 118.8^{\circ} \mathrm{C}$, and $110.5^{\circ} \mathrm{C}$, and the overall presentation shows an increasing trend. The decomposition temperature in the high temperature region is $480.7^{\circ} \mathrm{C}, 408.4^{\circ} \mathrm{C}, 480.6^{\circ} \mathrm{C}, 489.2^{\circ} \mathrm{C}, 492.5^{\circ} \mathrm{C}, 502.6^{\circ} \mathrm{C}$, respectively. The decomposition temperature is reduced when the 3\% composite particles are added, because the added composite particles are filled in the coating to make the molecular chain of the coating be stretched and the chain [36] is easily broken at high temperature, so the decomposition temperature will decrease. When the amount of addition reaches $6 \%$, the composite particles are the main body of the coating. The thermal stability of the coating is increased by the high temperature resistant composite particles, and the decomposition temperature is increased. The final residues in the system were $7.17 \%$, $8.70 \%, 15.73 \%, 18.82 \%, 22.96 \%$ and $31.62 \%$ respectively, which basically accorded with the increasing trend of the composite particles. 


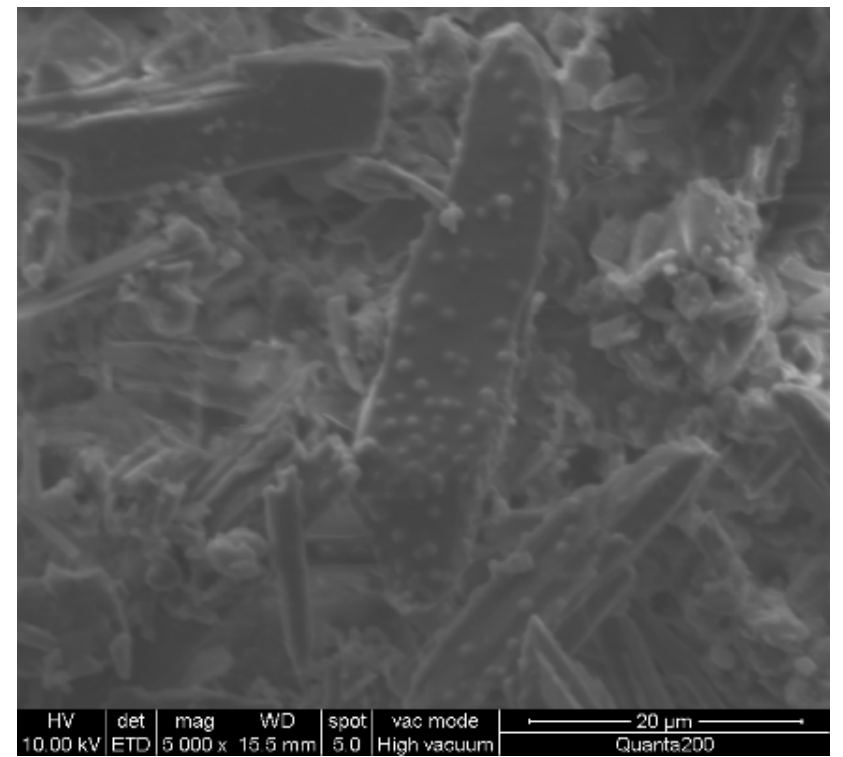

(a)

Figure 15: Nanostructures of UV curable Hybrid Coatings

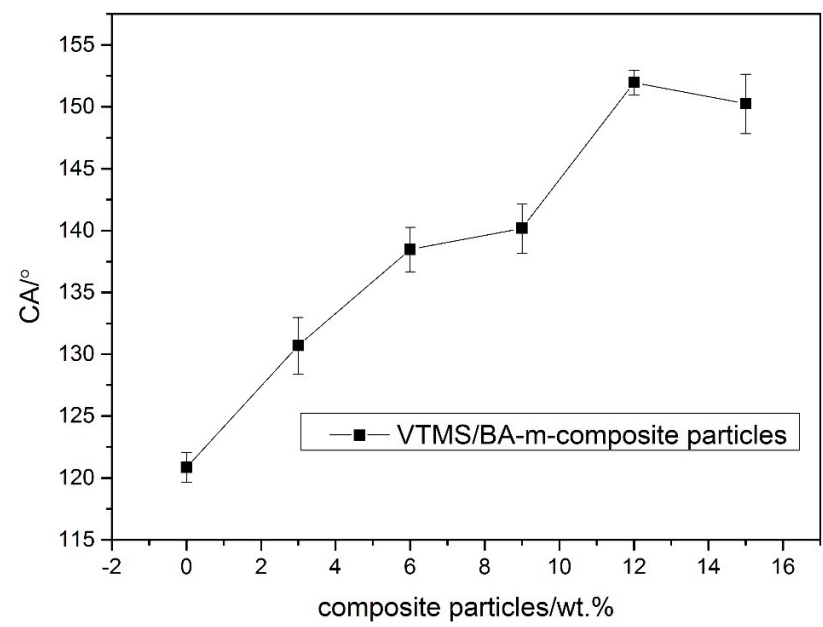

Figure 16: The influence of composite particles with different mass fractions on the contact angle of UV curable hybrid coatings

\subsubsection{FTIR spectra of UV curable Hybrid Coatings}

In order to study the reaction mechanism of VTMS/BA$\mathrm{m}$ - composite particle hybrid superhydrophobic coating, the infrared spectra of VTMS/BA-m-composite hybrid superhydrophobic coating before and after curing were compared (Figure 13). Figure a) is an infrared spectrum of a hybrid superhydrophobic coating containing 12\% VTMS/BAm-composite particles cured at different times, and Figure b) is a partial enlarged view of Figure a).

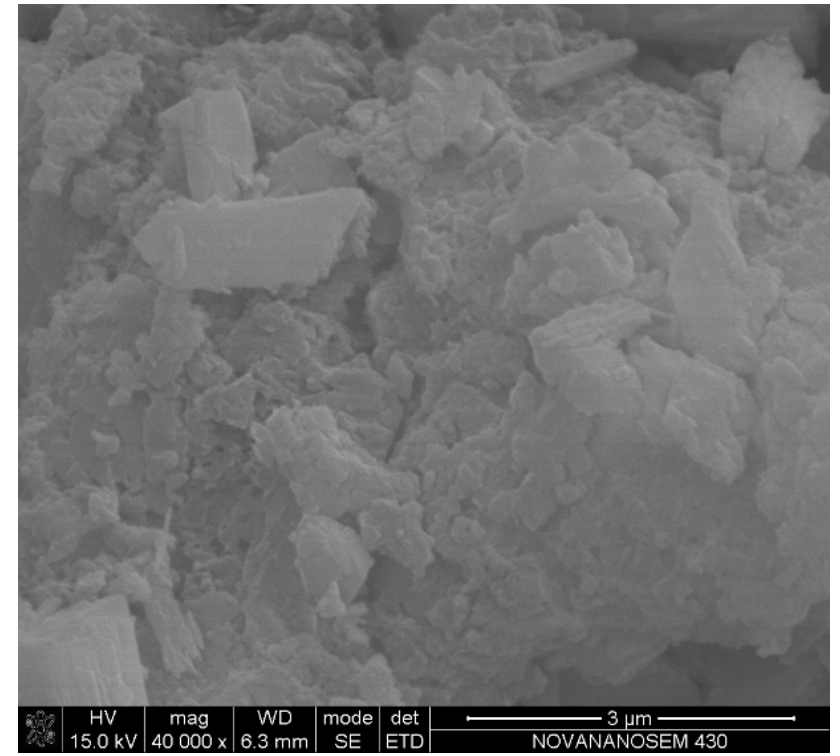

(b)

In Figure a), $2962 \mathrm{~cm}^{-1}$ is a stretching vibration peak of methyl C-H, $1619-1635 \mathrm{~cm}^{-1}$ is a stretching vibration absorption peak of $\mathrm{C}=\mathrm{C}$, and $1056 \mathrm{~cm}^{-1}$ is a stretching vibration absorption peak of Si-O-Si;As can be seen from the partial enlarged view of Figure b),before the curing, there is obvious stretching vibration absorption peak of carboncarbon double bond $\mathrm{c}=\mathrm{c}$ at $1619-1635 \mathrm{~cm}^{-1}$, which is caused by $\mathrm{C}=\mathrm{C}$ on vinyltrimethoxysilane and butyl acrylate. After curing, the peak disappeared, indicating that the polymerization occurred in the system under the initiation of ultraviolet light. Ultraviolet light induced a radical polymerization reaction in the system, and the double bond disappeared after polymerization.

\subsubsection{The Morphology of UV curable Hybrid Coatings}

In order to observe the surface morphology of UV curable superhydrophobic hybrid coatings prepared, the hybrid coatings with different mass fraction of composite particles were analyzed by scanning electron microscope. It can be seen that the surface morphology of the coatings has changed greatly after the doping of the composite particles, and there is no obvious composite structure on the coating with no composite particles (Figure 14a)). After adding $6 \%$ composite particles (Figure 14b)), the surface of the coating formed a number of protruding structures. The composite particles formed a micro nano structure on the surface. When the amount of addition reached $12 \%$ 


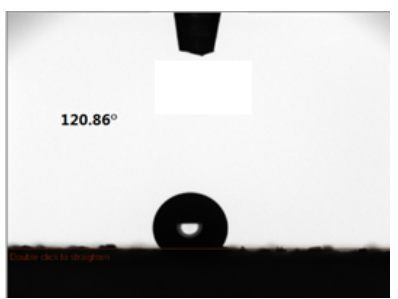

(a)

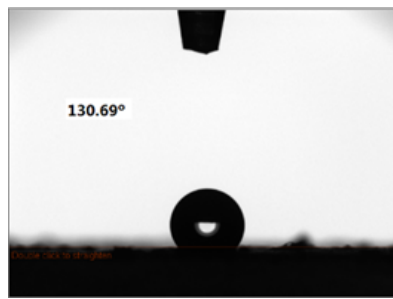

(b)

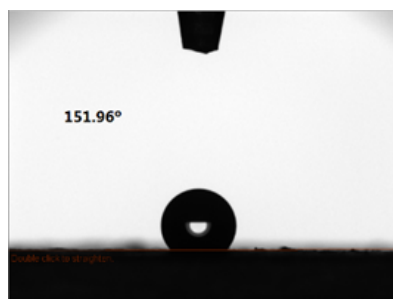

(e)

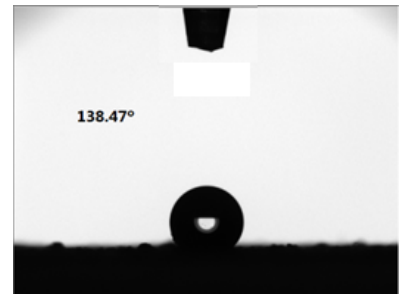

(c)

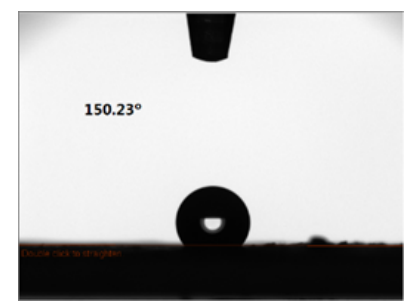

(f)

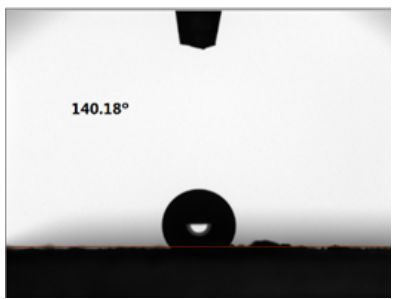

(d)

Figure 17: The contact angle of UV curable hybrid coatings with different composite particles content: a) $0 \%$; b) $3 \%$; c) $6 \%$; d) $9 \%$; e) $12 \%$; f) $15 \%$
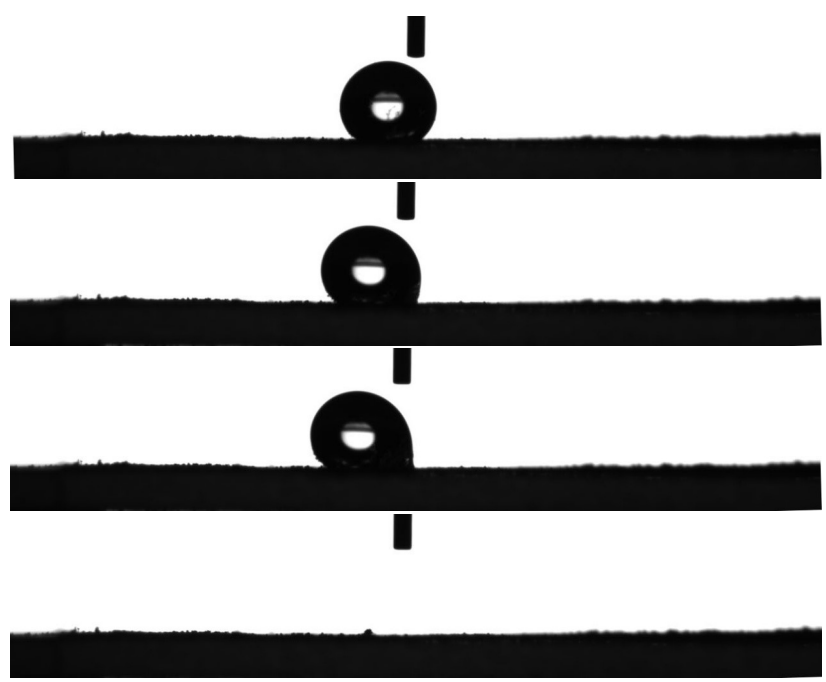

Figure 18: The SA photos of $10 \mathrm{ml}$ water-drop on the hybrid coating with $12 \mathrm{wt} \%$ composite particles

(Figure 14c)), the surface of the coating formed a similar porous surface structure. Combined with the unique micro nano structure (Figure 15) of the composite particles, it can make the coating become superhydrophobic. This superhydrophobicity can be explained by the Cassie model. Water droplets are on the surface of this composite coating and Because of the large amount of air in these holes, the network structure of the material is surrounded by air, and the water can not be entered into it, thus achieving superhydrophobicity.

\subsubsection{Analysis of water contact angle of UV curable Hybrid Coatings}

Figure 16 is the influence of composite particles with different mass fractions $(0 \%, 3 \%, 6 \%, 9 \%, 12 \%, 15 \%)$ on the contact angle of UV curable hybrid coatings. Figure 17 is the different contact angle of UV curable hybrid coatings with different composite particles content. Figure 18 is the SA photos of $10 \mu$ l water-drop on the hybrid coating with $12 \mathrm{wt} \%$ composite particles. It can be seen from Figure 16 that the influence of the content of the composite particles on the contact angle of the hybrid coating can be divided into two stages. In the first stage, with the mass fraction of the composite particles in the hybrid system changing from $0 \%$ to $12 \%$, the contact angle of the hybrid coating has been gradually increased to $151.96^{\circ}$ when the contact angle of the hybrid coating has never been added to the composite particles. This is due to the polymerization of vinyl trimethoxy silane and butyl acrylate when the UV curing is not added, and the addition of low surface energy active monomer vinyl trimethoxy can make the coating with a certain hydrophobicity. When the composite particles with different mass fraction were added, the composite particles formed a micro nano structure that conformed to the Cassie model on the surface of the coating, thus increasing the contact angle of the coating water. When the addition amount reached $12 \%$, the water contact angle reached $151.06^{\circ}$, the rolling angle reached $8.56^{\circ}$. And the water contact angle of the coating was over $150^{\circ}$, the rolling angle was below $10^{\circ}$, so the coating changed from hydrophobic- 
Table 2: The effect of composite particles with different mass fraction on the hardness and adhesion of UV curing coatings

\begin{tabular}{ccccccc}
\hline & \multicolumn{5}{c}{ VTMS/BA-m- composite particles } & UV curable Hybrid Coatings \\
\hline composite particles /wt\% & 0 & 3 & 6 & 9 & 12 & 15 \\
pencil hardness & $4 \mathrm{H}$ & $5 \mathrm{H}$ & $6 \mathrm{H}$ & $7 \mathrm{H}$ & $9 \mathrm{H}$ & $9 \mathrm{H}$ \\
adhesion & Level 2 & Level 2 & Level 2 & Level 3 & Level 3 & Level 5 \\
\hline
\end{tabular}

ity to superhydrophobicity. In the second stage, the contact angle of the coated water drops slightly after the addition of more than $12 \%$, which is due to the excessive accumulation of composite particles on the coating surface and the saturation of the surface structure, so that the water contact angle of the coating remains to a certain level or even a little drop. On the whole, when the mass fraction of the composite particles is $12 \%$, the hybrid coating has a large water contact angle, that is, super hydrophobic.

\subsubsection{Analysis of mechanical properties of UV curable Hybrid Coatings}

Table 2 is the effect of composite particles with different mass fraction on the hardness and adhesion of UV curing coatings. The experimental results show that the addition of the composite particles can improve the pencil hardness of the UV curable Hybrid Coatings, because the composite particles have a certain rigidity and hardness, and they are added to the coating to support the coating and give the coating a good hardness. When the addition amount reached $6 \%$, the adhesion of the composite particles had no significant effect on the adhesion of the coating, but the adhesion of the film was weakened when the amount of addition was over $6 \%$. This is because the addition of the composite particles to the coating destroys the order of the coating, and the adhesion of the coating to the coating is poor, so it is easily destroyed and the adhesion is reduced.

\section{Conclusions}

(1) In general, through characterization and performance testing, a new method of preparation of composite particles was studied. A hydrophobic composite particle was prepared by the mechanochemical effect of high pressure homogenizer on wollastonite and POSS-triol.

(2) The optimized composite particles were added to the UV curable coatings with VTMS/BA, and the super hydrophobic UV curable coatings were prepared.
(3) By studying the effect of different mass fraction of composite particles on the water contact angle of the coating, it is found that when the mass fraction of the composite particles rises from $0 \%$ to $12 \%$, the contact angle of the hybrid coating increases, the highest can reach $151.96^{\circ}$, and the water contact angle is little changed after more than $12 \%$. When the addition of composite particles reached $12 \%$, the mechanical properties of the coating were relatively high and the adhesion decreased little.

(4) The raw materials used in wollastonite are large and easy to obtain. The coating has certain prospects in industrial production.

Conflict of Interests: The authors declares that there is no conflict of interest regarding the publication of this paper.

The data availability statement: The data used to support the findings of this study are available from the corresponding author upon request.

The funding statement: Feng Xue has funded this study.

\section{References}

[1] Freudig B, Tesch S, Schubert H. Production of Emulsions in High Pressure Homogenizers Part II: Influence of Cavitation on Droplet Breakup[J]. Engineering in Life Sciences, 2010, 3(6):266-270.

[2] Håkansson A. Dynamic Modelling of Emulsification in HighPressure Homogenizers[]]. 2011.

[3] Chen Wanting. Preparation and characterization of silica coated composite particles coated with wollastonite [D]. University of Science and Technology Liaoning, 2015.

[4] Li. Influence of mineral surface properties on structure and properties of mineral $/ \mathrm{TiO}_{2}$ composite particles [D]. China University of Geosciences (Beijing), 2010.

[5] Lapík, Lubomír, Maňas, David, Lapíková, Barbora, et al. Effect of filler particle shape on plastic-elastic mechanical behavior of high density poly(ethylene)/mica and poly(ethylene)/wollastonite composites[]]. Composites Part B: Engineering, 2018, 141:92-99.

[6] Law K Y. Definitions for Hydrophilicity, Hydrophobicity, and Superhydrophobicity: Getting the Basics Right[]]. Journal of Physical Chemistry Letters, 2014, 5(4):686. 
[7] Hou Y P, Feng S L, Dai L M, et al. Droplet Manipulation on Wettable Gradient Surfaces with Micro-/Nano-Hierarchical Structure[J]. Chemistry of Materials, 2016, 28(11).

[8] Dr X F, Jin Z P, Lei J P. The Fabrication and Switchable Superhydrophobicity of TiO2 Nanorod Films[]]. Angewandte Chemie, 2005, 44(32):5115-5118.

[9] Mechanical Grinding Preparation and Characterization of $\mathrm{TiO}_{2}$ Coated Wollastonite Composite Pigments.

[10] Eum S C, Kim J H, Lee J K. Comparative Study of the Bioactivity of Hydroxyapatite and Wollastonite Coatings[]]. Journal of Nanoscience \& Nanotechnology, 2017, 17(6):3909-3912.

[11] Zhouwen J, Ronghuan W, Jianhua S, et al. Nonstoichiometric wollastonite bioceramic scaffolds with core-shell pore struts and adjustable mechanical and biodegradable properties[J]. Journal of the Mechanical Behavior of Biomedical Materials, 2018, 88:140-149.

[12] Min Y, Jun Y S. Wollastonite carbonation in water-bearing supercritical CO 2 : Effects of water saturation conditions, temperature, and pressure[J]. Chemical Geology, 2018:S000925411830024X.

[13] Chen Z , Zhai J , Wang D , et al. Bioactivity of hydroxyapatite/wollastonite composite films deposited by pulsed laser[]]. Ceramics International, 2018:S0272884218305613.

[14] Yaser Greish, Nuha Attia, Abdel-Hamid Mourad , et al. Formation and Biomimetic Deposition of Bone-like Hydroxyapatite on Wollastonite-gypsum Composites[J]. Journal of Bionic Engineering,2018,894-906.

[15] Hou X, Zhang Y, Ding H, et al. Environmentally friendly wollastonite@TiO 2, composite particles prepared by a mechanochemical method[J]. Particuology, 2018:S1674200118300282.

[16] Molkenova A, Taniguchi I. Preparation and characterization of $\mathrm{SiO2} / \mathrm{C}$ nanocomposites by a combination of mechanochemicalassisted sol-gel and dry ball milling processes[J]. Advanced Powder Technology, 2015, 26(2):377-384.

[17] Yamada H, Saitou T, Kurimoto Y. Characteristics of Benzylated Wood Meal Prepared by a Mechanochemical Method[J]. Mokuzai Gakkaishi, 2015, 61(2):67-73.

[18] Li. Influence of mineral surface properties on structure and properties of mineral $/ \mathrm{TiO}_{2}$ composite particles [D]. China University of Geosciences (Beijing), 2010.

[19] Chen Wanting. Preparation and characterization of silica coated composite particles coated with wollastonite [D]. University of Science and Technology Liaoning, 2015.

[20] Andreas H . Flow Pulsation Plays an Important Role for HighPressure Homogenization in Laboratory-Scale[]]. Chemical Engineering Research and Design, 2018:S0263876218304593-.

[21] Duan J, Hu G, Cao Y, et al. Synthesis of high-performance FeMg-co-doped LiMnPO 4 / C via a mechano-chemical liquid-phase activation technique[J]. Ionics, 2016, 22(5):609-619.
[22] Bo J, Yanbin S, Guimei L, et al. Nanoemulsion prepared by homogenizer: The CFD model research[]]. Journal of Food Engineering, 2019, 241:105-115.

[23] Gomide O C, Carvalho André, Marcus C, et al. High-pressure microfluidization as a green tool for optimizing the mechanical performance of all-cellulose composites[]]. ACS Sustainable Chemistry \& Engineering, 2018:acssuschemeng.8b01855-.

[24] Freudig B, Tesch S, Schubert H. Production of Emulsions in High-Pressure Homogenizers - Part II: Influence of Cavitation on Droplet Breakup[]]. Engineering in Life Sciences, 2010, 3(6):266270.

[25] Solving the 'mystery' of UV curing[J]. Metal Finishing.

[26] D.K. Chattopadhyay, K.V.S.N. Raju. Structural engineering of polyurethane coatings for high performance applications [J]. Progress in Polymer Science, 2007, 32(3):352-418.

[27] John R Arnolda, Gary Voelkera and Allen Shariatya. UV Coating Processes to Enhance Li Ion Battery Performance and Reduce Costs[]]. ECS Transactions, 2017, 80(10):397-416.

[28] HUANG, FENG. Effect of Organosilicon Coating Containing Light Stabilizer on UV Aging Resistance of Bitumen[J]. Journal of Wuhan University of Technology, 2010(17):83-88.

[29] Liu H B, Lin F, Zhang W Y. Synthesis and Characterization of UV-Thermal Dual Hybrid Curable Organosilicon Modified Epoxy Monoacrylates[J]. Applied Mechanics \& Materials, 2012, 152154:657-660.

[30] Garcia E, Miranzo P, Sainz M A. THERMALLY SPRAYED WOLLASTONITE AND WOLLASTONITE-DIOPSIDE COMPOSITIONS AS NEW MODULATED BIOACTIVE COATINGS FOR METAL IMPLANTS[J]. Ceramics International, 2018:S0272884218309738.

[31] Borchardt J K. Silica coats give strong nanotube composites : Nanotechnology[J]. Materials Today, 2005, 8(4):18-18.

[32] Ranjbar Z, Rastegar S. The influence of surface chemistry of nanosilica on microstructure, optical and mechanical properties of the nano-silica containing clear-coats[J]. Progress in Organic Coatings, 2009, 65(1):125-130.

[33] Hu Jiankun. Preparation and Characterization of POSS Monomers and Their Utilization in Aqueous Polyurethane Dispersions [D]. Wu Han University, 2013.

[34] Zeng K, Wang L, Zheng S, et al. Self-assembly behavior of hepta(3,3,3-trifluoropropyl) polyhedral oligomeric silsesquioxane-capped poly( $\varepsilon$-caprolactone) in epoxy resin: Nanostructures and surface properties[J]. Polymer, 2009, 50(2):685-695.

[35] Chen Wanting. Preparation and characterization of silica coated composite particles coated with wollastonite [D]. University of Science and Technology Liaoning, 2015.

[36] Chen Qian. Super hydrophobic in-situ modification of precipitated silica and its application in UV curable coatings [D]. South China University of Technology, 2013. 